\title{
Literatura antropológica en Chile: ¿Una literatura intercultural?*
}

\author{
Anthropologic literature in Chile: An intercultural literature?
}

\author{
Pilar Valenzuela Rettig \\ Universidad de La Frontera, Temuco, Chile. Correo electrónico: valenzuela.pilar@gmail.com
}

La literatura antropológica en Chile es una textualidad novedosa, interdisciplinaria y ambigua, cuyo estudio es reciente y escaso. En este trabajo la relacionamos, a nivel teórico, con la literatura intercultural en Chile, bajo la hipótesis de que la literatura antropológica puede considerarse una manifestación de la literatura intercultural. Para tal efecto se analiza el carácter intercultural de la literatura antropológica y las estrategias textuales que comparte con la literatura intercultural.

Palabras clave: literatura antropológica, literatura intercultural, interculturalidad, otredad, interdisciplinariedad

The anthropological literature in Chile is an innovative, interdisciplinary and ambiguous textuality, whose study is recent and sparse. In this paper we relate a theoretical level, this anthropologic literature with intercultural literature in Chile under the hypothesis that the anthropological literature can be considered a manifestation of intercultural literature. For such an effect there is analyzed the intercultural character of the anthropologic literature and the textual strategies that he shares with the intercultural literature.

Key words: anthropologic literature, intercultural literature, intercultural, otherness, interdisciplinarity

\section{INTRODUCCIÓN}

Tanto la literatura antropológica como la intercultural en Chile son recientes y su desarrollo teórico también es incipiente, novedoso y escaso. El objetivo general de este trabajo es profundizar en el análisis del aspecto intercultural de la literatura antropológica en relación con la teoría de la literatura intercultural y las estrategias textuales que comparten ambas literaturas, que hacen viable la hipótesis de que la

* Este trabajo forma parte del proyecto FONDECYT Postdoctorado $2014 \mathrm{~N}^{\circ} 3140616$ "Literatura antropológica en Chile: Una literatura intercultural", del cual la autora es investigadora responsable. 
literatura antropológica en Chile corresponde a una manifestación de la literatura intercultural ${ }^{1}$.

La literatura antropológica en Chile es una manifestación textual creada por un sujeto antropólogo o arqueólogo que, como parte de su trabajo de campo, entra en contacto con otro. Sostenemos que es de carácter intercultural, por cuanto el sujeto se expresa desde su integridad, no sólo desde su rol profesional, creando un texto interdisciplinario que presenta estrategias de índole literario (subjetivo, emotivo, de lenguaje figurado) y científico (objetividad, conocimiento, tópicos de las ciencias sociales).

Para ahondar en esta problemática, nuestro interés se centra en desambiguar el concepto de interculturalidad: ¿de qué hablamos al referirnos a interculturalidad?; identificar los principales postulados de la literatura intercultural en Chile: ¿qué aspectos definen qué texto puede considerarse parte de este corpus? y; establecer si la literatura antropológica en Chile presenta estos aspectos: ¿puede considerarse la literatura antropológica en Chile una literatura intercultural?

\section{Literatura antropológica en Chile: Una teoría Reciente}

La literatura antropológica en Chile fue identificada y presentada a la comunidad literaria del país por el académico Iván Carrasco, de la Universidad Austral de Chile, en el año 2010, cuando inicia el proyecto de investigación "Literatura antropológica en Chile", financiado por el Fondo Nacional de Desarrollo Científico y Tecnológico (FONDECYT), y publica, junto al co-investigador Miguel Alvarado, en ese entonces académico de la Universidad de Playa Ancha, el artículo "Literatura antropológica chilena: Fundamentos" en la revista Estudios Filológicos ${ }^{2}$. En resumidas cuentas, Carrasco (2010: 14) afirma que se trata de un conjunto de textos literarios de carácter principalmente etnográfico, escritos por antropólogos y arqueólogos contemporáneos, textos mediacionales en busca de nuevas vivencias y modos de conocimiento, como la intuición creadora del poeta o novelista. Surge en el desarrollo de la escritura antropológica y puede considerarse un sector de la literatura chilena por su parcial analogía temática y estilística con la textualidad literaria moderna y postmoderna, pero sin perder sus cualidades etnográficas y etnológicas. En ella se presenta la reiteración de temáticas como la del otro diverso, la importancia del viaje para obtener saberes y experiencia, la descripción detallada de situaciones de contacto intercultural e interétnico, diversos indicios de la formación profesional de los autores-narradores, y la perspectiva o punto de vista del antropólogo que busca datos para una monografía o investigación (Carrasco 2012; Valenzuela 2013a).

Es un discurso que remite a dos órdenes de pensamiento, literario y antropológico, y, según Carrasco y Alvarado (2010: 10), constituye una modalidad de "mutación disciplinaria": estrategia que consiste en modificar las reglas, modalidades, materias

\footnotetext{
Al ser teorías "recientes, novedosas y escasas" se encuentran en constante cuestionamiento por parte del campo académico literario y también el antropológico. Diversas instancias de debate, principalmente en congresos, favorecen la revisión, justificación y/o corrección de diversos aspectos teóricos. Así surge le necesidad de investigar a profundidad tanto el carácter intercultural de la literatura antropológica, como la relación de ésta con la teoría de literaturas interculturales.

2 Este artículo fue publicado en el número 46 de la revista. En trabajos previos, como el de Valenzuela (2012), se considera como autor sólo a Carrasco, debido a que Alvarado desarrolla una postura diferente en su línea de investigación, la cual corresponde a la antropología literaria y no a la literatura antropológica.
} 
y procedimientos de conformación de textos de una disciplina (artística, científica o filosófica) provocada por el traslado desde otra u otras disciplinas de igual o distinta condición, generando un estado de confusión de ámbitos disciplinarios, géneros y tipos discursivos (Carrasco 2002, 2003, 2007, Carrasco y Alvarado 2010). Por presentar esta dualidad de saberes, Carrasco y Alvarado (2010: 13-14) sostienen que es un tipo de discurso que conlleva las condiciones suficientes para ser leído simultánea o alternativamente como texto literario y/o texto etnográfico/etnológico.

Corresponden a textos escritos dentro del campo de las ciencias sociales en Chile, siendo recepcionados como parte del desarrollo de la antropología chilena. Se originan, básicamente, debido a la crisis disciplinar en las ciencias sociales y la búsqueda de otros lenguajes y formas etnográficas propias del desarrollo de la antropología postmoderna (Brunner 1997; Alvarado 2001; González 2003; Reynoso 2003). Dentro de este campo disciplinar los textos han sido definidos como "antropología poética" o "antropología literaria": ambas posturas consideran estos textos como un nuevo género discursivo en el campo de las ciencias sociales. Con respecto a la diferencia entre ellas, Alvarado considera que la antropología literaria supera el interés estético de la antropología poética, desarrollando una reflexión teórica que, a través de una estrategia de literaturización y de analogía estética con la literatura, llega a generar conocimiento tras la superación de la distinción sujetoobjeto, accionando un modo de acceder a la diversidad diferente. Además, sostiene que se ha desarrollado en Latinoamérica con anterioridad a la antropología poética (Alvarado 2005, 2009, 2011, 2014).

Se ha estimado que tanto la antropología poética como la literaria forman parte de un mismo proceso de experimentación textual por parte de antropólogos y arqueólogos que buscan un lenguaje que comunique lo "incomunicable" a través de la escritura antropológica tradicional (Valenzuela 2013a: 199). Parte de aquello que ha sido marginado de la escritura científica racional ha sido el propio sujeto: su participación personal e irrepetible en el trabajo de campo, su interioridad manifestada en sensaciones y/o reflexiones tanto sobre el otro como sobre sí mismo. Por tanto, se infiere una necesidad de reconocimiento del antropólogo/arqueólogo como sujeto que participa y se desenvuelve como un personaje más de la situación descrita, no sólo como observador u observador-participante.

Las creaciones se presentan, en el campo de las ciencias sociales, como textos cuyo estatuto científico es ambiguo. Al respecto, González (2003) expresa que con la antropología poética emerge el problema de la "subversión epistemológica", puesto que se sitúa como un modo de irracionalismo, fuera del margen y la comunidad científica. Similar es la postura de Quiroz (1998) al definir la antropología poética como una perspectiva "emergente", en cuanto estructura una forma nueva y distinta de hacer y escribir etnografía, al mismo tiempo que desestructura y deconstruye la escritura previa; postura que también manifiesta Gallardo (1997) al calificarla de "transgresión" y "emergencia" que se transmite por el entusiasmo del sujeto ante los hechos de indagación y el conocimiento.

Esta distinción entre diversas formas de hacer antropología, una de carácter "más científico" que cumple con las normas de escritura que establece el campo científico y otra de carácter "subversivo", corresponde a las relaciones de poder en y entre distintas antropologías que se dan a nivel mundial, no sólo en Chile. Esta situación de poder y distinción ha sido estudiada por investigadores como Roberto Cardoso de Oliveira 
(Cit. en Restrepo 2012), quien propone los conceptos de antropologías metropolitanas o centrales versus antropologías periféricas; Esteban Krotz (2004) con el concepto de antropologías del sur; y Eduardo Restrepo con el de antropologías disidentes, pretendiendo completar las nociones y teorías anteriores, junto a otras como la de antropologías subalternizadas (Restrepo 2012). En gran medida, los conocimientos generados en la "periferia", en relación al sistema mundial de la antropología (sistema que define la política de producción, difusión y el consumo de ideas sobre otros pueblos y culturas), están destinados a los espacios "periféricos" en que se producen, salvo que corresponda a los parámetros del sistema (Kuwayama Cit. en Lins 2011: 72). Ante esta situación responden las teorías anteriores y la de antropologías mundiales, proyecto político de Eduardo Restrepo y Arturo Escobar, que en específico considera que:

lejos de asumir que existe una posición privilegiada desde la cual puede producirse una "antropología real" (en singular), y con relación a la cual se definen todas otras antropologías, "las antropologías mundiales" buscan tomar en serio la múltiple y contradictoria historia social y los localismos sociales, políticos y culturales de las diferentes comunidades de antropólogos y sus antropologías (Cit. en Lins 2011: 67-77).

Siguiendo estas posturas, puede entenderse que estas antropologías desarrolladas en Chile corresponden a una de las tantas variedades de antropologías mundiales, por lo que no necesariamente poseen un carácter marginal en cuanto al sistema mundial de la antropología. Sin embargo, se les inscribe un estado de marginalidad, en gran medida, por el carácter interdisciplinar de sus textos: al poseer un carácter literario entra en el espacio de la ambigüedad disciplinaria, y así como "se aleja" del campo antropológico, se "acerca" al literario.

Desde el campo de la ciencia literaria, la lectura de los textos se ha basado en una concepción abierta, regional, conceptual y operativa de literatura que obedece al paradigma semiótico de las teorías del texto literario. Estas teorías se basan en la premisa del doble código en el objeto del texto: uno lingüístico y otro donde confluyen varios sistemas culturales. Bajo las concepciones de este paradigma, la literatura corresponde a un conjunto de textos cuya literariedad obedece a procesos de semiotización realizados por una comunidad literaria en un momento histórico determinado (Valenzuela 2013a: 45-50).

Rehusando una definición universal, esencial y estable de la literatura, se ha establecido e iniciado un proceso de canonización de la literatura antropológica en Chile en el campo de la ciencia literaria nacional. Esta literatura se ha definido por presentar un código de carácter interdisciplinario e intercultural, sin embargo, al ser una literatura en proceso de canonización y cuya teoría es reciente y en construcción, surge la necesidad de estudiar en profundidad y justificar a nivel teórico y de análisis textual su carácter intercultural.

\section{Interculturalidad: ¿De QuÉ hablamos?}

Uno de los mayores problemas al hablar de interculturalidad es la carencia de fijación terminológica al respecto (Cruz 2013; Giménez y Malgesini 2000; Rodrigo Alsina 2003, 2012). En gran medida esta falta de acuerdo se debe a que la interculturalidad es un objeto de estudio transdisciplinario (Rodrigo Alsina 2012: 219) y, 
para mayor confusión, existen diversas narrativas con respecto a qué es cultura (García Canclini 2004: 31-39; Giménez y Malgesini 2000: 83-91).

Ante tal ambigüedad se hace indispensable delimitar la definición a utilizar en el estudio, que se fija en relación al concepto que se infiere de la teoría de literatura intercultural en Chile. Partimos por establecer una concepción histórica y dinámica de las culturas, basada en que: a) éstas son procesos cuyas fronteras se encuentran en un continuo tránsito, por lo que no pueden ser consideradas monotradicionales (Fornet-Betancourt 2002: 127-129); y, b) se encuentran en constante proceso de construcción debido a que se componen en la permanente interacción de los seres humanos que conforman una comunidad de vida (Rodrigo Alsina 2012: 68).

Miquel Rodrigo Alsina (2012) expresa que para entender las culturas hay que evidenciar que "el ser humano es un ser básicamente cultural y que la cultura es una construcción del ser humano" (2012: 67). Por tanto, una persona nace, se socializa e interioriza una cultura ("su mundo"), y al constituir parte de ella ayuda a transmitirla, conservarla y transformarla; proceso que, nos dice el autor, sucede por la interacción comunicativa que se produce en el seno de cualquier comunidad de vida ${ }^{3}$.

Ahora bien, bajo esta mirada conceptual de cultura, hay que esclarecer el término multiculturalidad, ya que, como exponen Giménez y Malgesini (2000: 253), "la aparición del término de interculturalidad o interculturalismo parece motivado por las carencias de los de multiculturalidad y multiculturalismo para reflejar la dinámica social y para formular el objetivo de nuevas síntesis socioculturales". La multiculturalidad corresponde a una situación de hecho y/o una propuesta de organización social y política (Acevedo 2008: 144), aunque también puede ser entendida como una ideología (Rodrigo Alsina 2012: 74). Como hecho se refiere a la convivencia en un mismo espacio social de personas que se identifican con culturas diferentes (Giménez y Malgesini 2000: 18), situación que también se puede encontrar conceptualizada por pluriculturalidad (SERVINDI 2005: 25). Como proyecto político, en su sentido normativo, se refiere al respeto hacia las identidades culturales y se basa en dos principios básicos: el principio de ciudadanía (igualdad de derechos, responsabilidades y oportunidades), y el derecho a la diferencia o ciudadanía diferenciada (que implica el respeto a la identidad y los derechos de los pueblos y grupos socioculturales) (Acevedo 2008: 144).

La interculturalidad, además de ser vista como una situación concreta (las relaciones interculturales), corresponde a una propuesta de organización social y política que, junto con los principios de ciudadanía común y diferenciada que presenta la multiculturalidad, tiene el principio de "unidad en la diversidad" (Acevedo 2008: 147). En este último sentido, este término es considerado como un proceso en construcción, que es posible alcanzar a través de prácticas y acciones concretas y conscientes, siendo un desafío de las sociedades multiculturales (SERVINDI 2005: 30-31).

Conceptualmente, se habla de interculturalidad como un término en gestación, que se construye desde distintos campos, por ejemplo, la educación, la teoría de la comunicación y la política; se basa en una perspectiva dinámica de la cultura y

Esta postura es similar a la que propone Abdallah-Pretceille (2006) a través del concepto de "culturalidad", con el cual identifica el hecho de que las culturas tienen movimiento, diferentes celdas, y que son los trazos culturales los que son eficientes y no las estructuras. Para la autora, un concepto estable de cultura, basado en características y rasgos fijos, hace imposible el entendimiento de los fenómenos culturales inestables que hoy en día se dan producto de mezcolanzas, mestizajes y transgresiones culturales. 
culturas, y; se centra en el contacto y la interacción, la mutua influencia, el sincretismo y el mestizaje cultural (Giménez y Malgesini 2000: 258). Por tanto, es coherente con los postulados del mestizaje cultural presentados por Boukuos (Cit. en Rodrigo Alsina 2012: 50), basados en que toda nación es, en principio, un mosaico de culturas $\mathrm{y}$, por consiguiente, el mestizaje cultural es un hecho estructurante de la historia.

En cuanto a las relaciones interculturales se destaca que en éstas debe darse el reconocimiento mutuo, el intercambio de saberes y experiencias, y la convivencia social (SERVINDI 2005: 30). Estas relaciones se plasman en una comunicación intercultural que requiere de una competencia comunicativa y un cierto conocimiento de la otra cultura (Rodrigo Alsina 2012: 77), es decir, una competencia intercultural interpersonal que corresponde a "la habilidad para negociar los significados culturales y ejecutar las conductas comunicativas apropiadamente eficaces que reconocen las múltiples identidades de los interactuantes en un entorno específico." (Chen y Starosta Cit. en Rodrigo Alsina 2012: 163).

Dentro de las competencias que se pueden considerar como interculturales están aquellas que Earley y Ang (Cit. en Surian 2012: 211) distinguen en diez categorías: habilidades comunicativas, tolerancia a la frustración, empatía, abertura mental, flexibilidad, capacidad de saber enfocar una tarea o relación, postura positiva hacia el aprendizaje, tolerancia hacia estilos y culturas diferentes, conocimiento cultural y capacidad de tener éxito en contextos diferentes. Adicionalmente, se recalca que la competencia intercultural involucra elementos a nivel emotivo (o afectivo), cognitivo y conductual (o de comportamiento) (Rehaag 2006: 6; Rodrigo Alsina 2012: 163).

En el aspecto emotivo se habla de competencia intercultural emotiva que se demuestra cuando las personas son capaces de proyectar y de recibir las respuestas emocionales positivas antes, durante y después de las interacciones interculturales (Chen y Starosta Cit. en Rodrigo Alsina 2012: 239). Esta competencia implica, según Rodrigo Alsina (2012: 240-241), la presencia de una motivación que se traduce en el deseo de conocer, aprender, romper las barreras culturales y re-conocernos, es decir, de re-construir nuestra identidad en relación al conocimiento del otro.

Medina (2004) reflexiona sobre las emociones como barreras y accesos a la diversidad cultural. Dentro de su trabajo enfatiza que en la medida en que hay diversidad cultural hay también diversidad de referentes emocionales y vocabularios emocionales que afectan las relaciones interculturales. Para esta relación se necesita poseer confianza (ambos interlocutores están interesados en superar las barreras), aceptación y empatía, para entender al otro, comprender y compartir.

\section{Literatura interculturAl y SUS PUNTOS DE ENCUENTRO CON LA ANTROPOLÓGICA}

La literatura intercultural, al igual que la antropológica, se ha presentado y desarrollado teóricamente a partir del trabajo de investigación del académico Iván Carrasco. Como parte de un proyecto FONDECY titulado "Canonizaciones e identidades en la literatura chilena" del 2004, a partir del cual publica el artículo "Literatura intercultural chilena: Proyectos actuales" (2005) en la Revista Chilena de Literatura. En este trabajo presenta los proyectos que cataloga de carácter intercultural desarrollados dentro de la literatura chilena de la época: la poesía etnocultural, la literatura del exilio y la de los grupos inmigrantes. 
Para Carrasco (2005: 63) estas literaturas tienen, a lo menos, dos antecedentes. En primer lugar, el origen intercultural de la cultura hispanoamericana, que nace en el proceso de cruce, asimilación, superposición y síntesis de elementos indígenas y europeos. En segundo lugar, la posibilidad de ampliar el desarrollo de la literatura a partir del surgimiento de la mutación disciplinaria, lo cual se presenta como resultado de la inestabilidad de la teoría y del proceso de literatura en Chile (Carrasco 2003, 2007).

Las literaturas interculturales obedecen a un concepto dinámico de interculturalidad, que es definido por Carrasco como "un proceso de interacción entre sociedades diferenciadas en contacto y/o comunidades o grupos en el marco de una sociedad global, en cuanto dicha interacción provoque modificaciones recíprocas y cree espacios culturales nuevos resultantes de la integración y transformación de elementos culturales heterogéneos" (2005: 65). Distingue, desde la perspectiva de los contextos que se incluyen para la realización de la interculturalidad, la interculturalidad sociocultural y textual. Mientras la primera corresponde a la que se desarrolla en la convivencia del ámbito social; la textual corresponde al proceso de comunicación entre personas y grupos mediante discursos o textos de distinta condición étnica y cultural, los cuales se manifiestan oralmente o por escrito en contextos de comunicación intercultural. Dentro de estos discursos, Carrasco (2005) expresa que es el literario el que ha logrado un mayor desarrollo, definiendo la interculturalidad literaria como:

la relación entre etnias, culturas, lenguas y dialectos producida en textos reconocidos como literarios por la institución literaria chilena, que se modifican y transforman en la compleja situación de interacción o reciprocidad en que se hallan. (...) Se trata, por tanto, de procesos de construcción y redefinición textual e identitaria en los que se confunden lenguas, dialectos y discursos aborígenes, extranjeros y criollos, además de retóricas y poéticas tradicionales e innovadoras (2005: 68).

Sin distinguir entre los tres proyectos que identifica Carrasco, la estrategia discursiva esencial que determinamos es la de dar cuenta de una situación intercultural como macroestructura semántica o tema ${ }^{4}$. $\mathrm{Al}$ respecto, la literatura antropológica ha sido caracterizada como interdisciplinaria e intercultural: es una literatura que se mueve en pares, entre dos disciplinas (que también pueden llegar a entenderse como "culturas disciplinares"), y entre dos culturas, la del sujeto y la del otro. Un aspecto fundamental de la textualidad, destacado sobre todo desde la mirada de las ciencias sociales, es que corresponde a una manifestación de un proceso antropológico centrado en el encuentro y el conocimiento del otro, ya sea desde una situación de trabajo de campo (como delimita la teoría de la antropología poética), o desde una situación textual (como posibilidad que defiende la antropología literaria).

Dentro del escaso estudio de la literatura antropológica ya ha sido incluido el tema de la interculturalidad, en tanto se ha demostrado, a partir del análisis textual de diarios de viaje y campo (Valenzuela 2013a), que el autor modelo es de carácter intercultural en cuanto es un antropólogo o arqueólogo que realiza un viaje hacia la otredad: viaje donde se hace presente un encuentro con el otro, así como la mirada antropológica y personal del sujeto que se manifiesta como un narrador protagonista

Para van Dijk (1993: 43-57) las macroestructuras semánticas son la reconstrucción teórica de nociones como tema o asunto del discurso y dan cuenta del contenido global de éste. 
de la historia. En el mismo estudio, se estableció (a través de análisis de marcos discursivos) la necesidad de encontrar al otro y a sí mismo a través de la relación con el otro, y de poder transmitir esta experiencia de una forma más completa que la que brinda la etnografía tradicional. Esta experiencia de contacto se definió como intercultural en la medida en que el sujeto se relaciona desde su intimidad-integridad, no sólo desde su rol profesional.

Consideramos que tanto las literaturas interculturales como las antropológicas pueden denominarse interculturales, toda vez que sobrepasan la otredad, entendida como perspectiva metodológica. La otredad corresponde al objeto de estudio de la antropología, en cuanto el ser humano se hace preguntas por el ser humano o sobre lo humano. Según Krotz (2004), no se refiere a una simple diferenciación, sino que se vincula con la experiencia de lo extraño (paisajes, climas, plantas, animales, formas, colores, sonidos, etc.).

Respecto al conocimiento del otro y el trabajo antropológico, Augé (1996) reflexiona y pone en evidencia la situación que denomina paradoja fundacional de la etnología: el hecho de que se le pida al antropólogo que entienda las otras culturas desde el interior y el exterior al mismo tiempo, siendo distanciada en tanto el reconocimiento de la alteridad requiere del alejamiento del observador ante lo observado, pero también se le conmina a que sea participativa, de modo de poder contar con los datos necesarios para la interpretación de aquellos que pertenecen a otra sociedad, lo que no se lograría sino desde "dentro" de la sociedad. Así, al plantear que la literatura antropológica es intercultural, estamos afirmando que la mirada, perspectiva y/o relación del sujeto con su objeto de estudio supera la otredad, en la medida en que supera la paradoja de exterioridad e interioridad, a través, precisamente, de la interculturalidad. El sujeto antropólogo-literato logra romper con las barreras disciplinarias y plantearse como un sujeto en una situación intercultural, donde no sólo se centra en la otredad como objeto de estudio, sino también en el "yo" y el "yo en relación con el otro".

En un estudio realizado en torno al carácter intercultural de la literatura antropológica, en base al análisis del libro El umbral roto. Escritos en antropología poética (1995) de Juan Carlos Olivares ${ }^{5}$, se concluye que: el texto presenta una carácter intercultural toda vez que el sujeto textual se relaciona con el otro a nivel integral (tanto profesional como emocionalmente), por lo que debe recurrir a estrategias interdisciplinarias para poder comunicarse; en cuanto macroestructura semántica se desarrolla el "encuentro con el otro" y los "puntos de unión" que implican una participación integral (el pasado en común, el deseo similar, el vacío ante la religiosidad católica y la práctica del latúe); respecto a los marcos discursivos se manifiesta un proyecto escritural de carácter etnográfico y literario, basado en la búsqueda de la "verdad etnográfica", entendida como una práctica antropológica que se origina de la certeza en torno a la inclusión de todos los estilos de vida ante una realidad total donde el antropólogo no puede colocar una distancia real con el objeto de estudio.

Bajo esta concepción de "realidad total" se produce una participación integral donde el sujeto pasa a ser el otro, a mirar desde el otro pero no a partir del desarraigo, más bien entendiendo que luego de la experiencia de trabajo de campo su estilo de

Texto considerado como elemento clave a nivel metatextual de la antropología literaria. 
vida ha cambiado, y que el trabajo de campo (entendido como viaje) implica un ir donde el otro, encontrarse con el otro, ser el otro y luego mirarse, mirar cómo ha cambiado a partir de la experiencia. Por tanto, en El umbral roto... no se presenta una postura centrada en la otredad, por el contrario, corresponde a una postura donde el sujeto se hace visible y partícipe de una relación intercultural (Valenzuela 2013b).

A pesar de estos avances teóricos respecto a la relación interculturalidad-literatura antropológica, se reconoce la necesidad de justificar el carácter intercultural de la literatura antropológica a través de un análisis textual que contenga conceptos claves presentes en la teoría de la interculturalidad, muchos ya presentados en este trabajo, tales como: relación intercultural, diálogo, competencias interculturales interpersonales y emotivas. Se trata de conceptos que ningún estudio referido a literaturas interculturales ni antropológicas ha incluido, seguramente debido al reciente y escaso desarrollo teórico y crítico de estas literaturas. Aun así, se ha podido justificar un carácter intercultural en la literatura antropológica que, entendida como una situación de contacto-conocimiento de sí mismo y del otro en la relación, la vincula con los proyectos de literatura intercultural en Chile.

En cuanto a la relación de la literatura antropológica con los proyectos de literatura intercultural en Chile identificados por Carrasco (2005), consideramos que la literatura antropológica presenta mayor similitud con la poesía etnocultural. Ésta, según el crítico, se compone por tres proyectos de escritura que se desarrollan en el sur del país: la de los mapuches, de los escritores mestizos europeos y de los chilotes (2005: 69-74) ${ }^{6}$. En esta línea, planteamos que la literatura antropológica comparte las principales características de la poesía etnocultural (Carrasco 2005): 1) la codificación doble o plural, en sus variantes de doble registro y collage etnolingüístico; 2) la intertextualidad transliteraria, y; 3) la enunciación sincrética, intercultural o heterogénea.

En cuanto a la doble codificación, la literatura antropológica suele presentarla en conexión con la interdisciplinariedad y la interculturalidad. Esta característica sería una de las distinciones de esta literatura como manifestación de literatura intercultural, en cuanto el doble registro no se despliega únicamente por el carácter y/o situación intercultural presente en él (por contener términos en dos o más códigos lingüísticos, por ejemplo), sino también en la medida en que presenta una dualidad de códigos disciplinarios, correspondientes al antropológico y literario. En el estudio de Valenzuela (2013a) se consideran estas dualidades de codificación en torno al carácter fragmentario de los diarios, por cuanto se presenta una fragmentación idiomática y otra en relación con el uso de citas, notas y bibliografía (que obedece a la doble codificación disciplinar).

Ahora bien, esta expresión de doble codificación se relaciona directamente con la intertextualidad transliteraria presente en los textos etnoculturales, definida por Carrasco como "la relación transtextual con textos y textualidades de índole no artística pero incluidos en su circuito comunicativo por tradición (históricos, cronísticos, científicos, documentales, religiosos)" (2005: 72). En el caso de la literatura antropológica, esta intertextualidad transliteraria se vincula con la interculturalidad,

Cabe mencionar que ante el término de "poesía etnocultural", se presentan otros en oposición, como el de "poesía nacional mapuche" de Jaime Huenún (Mansilla 2011) u "oralitura" de Elicura Chihuailaf (González 1999). Sin embargo, optamos por la teoría presentada por Carrasco por abarcar el problema de las literaturas interculturales en conjunto (no sólo las mapuches), ofreciendo un marco teórico pertinente al presente estudio, a pesar de que aspectos teóricos como éste o el de "mutación disciplinar" puedan ser fruto de debate o controversia. 
ya que se presentan textos "culturales" (relatos personales, creenciales, de la estructura social y mapas, entre otros) de la cultura con la que se está en contacto, así como textos antropológicos. En particular, en esta literatura la transtextualidad es un elemento relevante en cuanto se constituye por el carácter interdisciplinario e intercultural: la transtextualidad no sólo es "transliteraria" por presentar una relación textual con elementos culturales, sino también "literaria" por desarrollarse en un texto de carácter interdisciplinario que, al presentar dos áreas de conocimiento, muestra intertextualidades hacia ambas disciplinas (Valenzuela 2013a: 137-150).

Por último, la enunciación es sincrética, intercultural o heterogénea por la presencia de las voces de los sujetos antropólogos y de los informantes (los otros), que se explayan como narradores o dialogantes. También se cumple toda vez que el sujeto antropólogo se constituye como un sujeto "ambiguo", que se debate entre dos ciencias y dos culturas, yendo y viniendo de una a otra, experimentando ser otro y experimentando una situación de inestabilidad que cuestiona constantemente su identidad, no sólo cultural, sino también profesional (la que podría llegar a leerse como una sub-cultura). Así, en línea con los postulados de Carrasco sobre la enunciación en la literatura etnocultural (2005: 71), se distingue un enunciado que incluye un sujeto heterogéneo con capacidad de integrar distintos saberes y puntos de vista etnoculturales, al tiempo que se presenta como investigador social, protagonista o partícipe étnica o socialmente implicado en los contenidos que despliega.

\section{Conclusiones}

Hablar de interculturalidad en literatura es una tarea difícil, sobre todo si se parte de la propia ambigüedad del concepto de interculturalidad. Sin embargo, en Chile se ha desarrollado una teoría de literatura intercultural, que deja de manifiesto que una sección de la literatura chilena desarrolla este tema, centrándose en la relación intercultural que se manifiesta en sus textos, específicamente, en cómo éstos muestran características textuales novedosas a partir de la situación de interculturalidad que experimentan los autores. Por tanto, se considera la interculturalidad a nivel textual y extratextual. En esta teoría sobre literatura intercultural, generada por Iván Carrasco, se considera un concepto dinámico e histórico de cultura, que permite asumir la interculturalidad como un hecho concreto (relaciones interculturales) que se pone de manifiesto a través de textos literarios, así como de un proyecto escritural novedoso que surge del intercambio de saberes de una persona que, identificándose con una cultura, aprende de otra en una relación intercultural.

A partir de los enunciados teóricos revisados, podemos establecer que desde los primeros estudios sobre la literatura antropológica se ha incluido la interculturalidad junto con la interdisciplinariedad como elementos claves. En dichos estudios se ha enfatizado que este tipo de literatura se caracteriza por presentar saberes antropológicos y literarios, a través de los cuales se conjugan los rasgos de objetividad/subjetividad y racionalidad/emoción. Es a través de la interdisciplinariedad, la unión de los saberes disciplinarios, y la libertad de experimentación en la escritura que el sujeto logra comunicar la experiencia intercultural. Sostenemos que la experiencia que manifiesta el sujeto a través de la textualidad es de carácter intercultural, en la medida en que hay una situación de contacto étnico y/o cultural en la cual se involucra integralmente. 
De esta manera, el sujeto experimenta la interculturalidad en tanto la situación de contacto implica un conocimiento (cognitivo/emocional) de sí mismo y del otro en la relación. Adicionalmente, la situación intercultural también conlleva un cambio en el sujeto y en la textualidad que produce para evidenciar el conocimiento que obtiene del trabajo de campo, puesto que se ve en la necesidad de crear un texto interdisciplinario, recurriendo a la mutación entre la antropología y la literatura, de modo de poder superar los límites del discurso científico y de mostrar cabalmente la situación experimentada.

A partir de estos enunciados podemos sostener que, a nivel teórico, la literatura antropológica corresponde a una manifestación textual que se incluye en los proyectos de literatura intercultural propuestos con anterioridad por Iván Carrasco. En esta dirección, comparte con la literatura etnocultural, de los inmigrantes y del exilio la estrategia de dar cuenta de una situación intercultural. La particularidad de la literatura antropológica corresponde a que la situación (como macroestructura semántica) se determina por el contexto del viaje y/o trabajo de campo antropológico, y su enunciación, por la interdisciplinariedad. Las otras estrategias que proponemos para definir la literatura antropológica como intercultural -a nivel de una primera investigación basada en estudios críticos y no de análisis textual-han sido determinadas a partir de su similitud con la poesía etnocultural: doble codificación, intertextualidad y enunciación sincrética, intercultural o heterogénea. Con respecto a la doble codificación, la literatura antropológica se distingue por presentarla tanto a nivel lingüístico (como la poesía etnocultural), como a nivel disciplinar, por constituirse a partir de códigos literarios y antropológicos. La intertextualidad se homologa a la estrategia de "intertextualidad transliteraria" que presenta la poesía etnocultural, no obstante, a partir de una textualidad "transdiciplinaria" la intertextualidad no puede ser catalogada como "transliteraria", lo que implicaría catalogarla como "literaria" y, en estricto rigor, se ha sostenido que al ser interdisciplinaria es literaria y antropológica al mismo tiempo, independiente de la lectura parcial que pudiese hacerse de ella. Por último, proponemos la estrategia de enunciación sincrética, intercultural o heterogénea, desde la particularidad que implica que el sujeto enunciativo se caracterice por ser interdisciplinario y por enunciar desde una situación intercultural.

\section{OBRAS CITADAS}

Abdallah-Pretceille, Martine. 2006. "Lo intercultural como paradigma para pensar la diversidad". Congreso Internacional de Educación Intercultural. Madrid, España. Recuperado el 10 de febrero de 2014, de http://www.uned.es/congreso-inter-educacion-intercultural/ pretceille_espanol.pdf

Acevedo, Saríah. 2008. "La interculturalidad: Sus orígenes como concepto y sus diferentes interpretaciones". En CANEK-Observatorio Cultural, La construcción de comunicación intercultural aplicada. Ciudad de Guatemala: El Librovisor. 139-193.

Alvarado, Miguel. 2001. La antropología poética chilena como textualidad híbrida. Tesis doctoral. Valdivia: Universidad Austral de Chile.

2005. "El espejo rápido: La consolidación de la antropología literaria chilena". Nueva Revista del Pacífico 50: 191-215.

2009. "La primera metalengua de una antropología literaria. Lecturas de Cortázar, una antropología poética de Néstor García Canclini”. La torre del Virrey (Valencia, España). 
Recuperado el 20 de febrero de 2014, de http://www.latorredelvirrey.org/viejaltv/libros/ libros_otono09/pdf/177.pdf

2011. La antropología literaria. Aportes para la generación de un lenguaje intercultural. Santiago: Cuarto Propio.

. 2014. El vuelo de la Calandria. Analogías estéticas y comprensión transcultural latinoamericana. Deutschland: Editorial Verlag.

Augé, Marc. 1996. El sentido de los otros. Barcelona: Paidós.

Brunner, José. 1997. "Sobre el crepúsculo de la sociología y el comienzo de otras narrativas".

En Facultad Latinoamericana de Ciencias Sociales, Sede Chile, Informe de actividades.

Celebración de los 40 años de FLACSO en América Latina. Recuperado el 20 febrero de 2014, de http://flacsochile.org/biblioteca/pub/publicos/1997/revista/002336.pdf

Carrasco, Iván. 2002. "Interdisciplinariedad, interculturalidad y canon en la poesía chilena e hispanoamericana actual". Estudios Filológicos 37: 199-210.

. 2003. "La antropología poética como mutación disciplinaria". Estudios Filológicos 38: 7-17.

. 2005. "Literatura intercultural chilena: Proyectos actuales". Revista Chilena de Literatura 66: 63-84.

. 2007. "La mutación disciplinaria: Un fenómeno de comunicación interdisciplinaria".

En Browne, Rodrigo, Breno Onetto y Víctor Hugo Valenzuela (Eds.), Diálogos cultura-

les. Interdisciplinas para la comunicación. Sao Paulo: Annablume. 17-26.

y Miguel Alvarado. 2010. "Literatura antropológica chilena: Fundamentos". Estudios Filológicos 46: 9-23.

. 2012. "Poesía antropológica de Ivonne Valenzuela". Anales de Literatura Chilena 17: 219-236.

Cruz, Edwin. 2013. "Multiculturalismo e interculturalismo: Una lectura comparada". Cuadernos Interculturales 11.20: 45-76.

Fornet-Betancourt, Raúl. 2002. "Filosofía intercultural en América Latina: Intento de introducción no filosófica”. En González, Graciano (Coord.), El discurso intercultural. Prolegómenos a una filosofia intercultural. Madrid: Biblioteca Nueva. 123-138.

Gallardo, Francisco. 1997. Arqueología y poesía. Santiago: LOM.

García Canclini, Néstor. 2004. Diferentes, desiguales y desconectados. Mapas de la interculturalidad. Barcelona: Gedisa.

Giménez, Carlos y Graciela Malgesini. 2000. Guía de conceptos sobre migraciones, racismo e interculturalidad. Madrid: Los Libros de la Catarata.

González, Yanko. 1999. De héroes civiles \& santos laicos. Palabra y periferia: Trece entrevistas a escritores del sur de Chile. Valdivia: Ediciones Barba de Palo.

. 2003. "Nuevas prácticas etnográficas: El surgimiento de la antropología poética". En Richard, Nicolás (Comp.), Movimientos de campo, en torno a cuatro fronteras de la antropología en Chile. Guatemala/Francia: ICAPI-Ecole des Hautes Etudes en Sciences Sociales. 185-202.

Krotz, Esteban. 2004. “Alteridad y pregunta antropológica”. En Movín, Mauricio, Ana Rosato y Victoria Arribas (Eds.), Constructores de otredad. Una introducción a la antropología social. Buenos Aires: Antropofagia. 16-21.

Lins, Gustavo. 2011. "La antropología como cosmopolítica. Globalizar la antropología hoy". En Grimson, Alejandro, Silina Merenson y Gabriel Noel (Comps.), Antropología ahora. Debates sobre la alteridad. Buenos Aires: Siglo XXI. 69-96.

Mansilla, Sergio. 2011. “'Palabras que van a dar al río de una poesía inútil'. Una aproximación a la poética de Jaime Huenún a partir de Puerto Trakl". Alpha 32: 11-27.

Medina, Pilar. 2004. "Las emociones como barreras y accesos a la diversidad cultural". Congreso Comunicación y Diversidad Cultural. Barcelona, España. Recuperado el 20 de febrero de 2014, de http://www.portalcomunicacion.com/dialeg/paper/pdf/35_alsina.pdf 
Olivares, Juan Carlos. 1995. El umbral roto. Escritos en antropología poética. Santiago: Fondo Matta-Museo Chileno de Arte Precolombino.

Quiroz, Daniel. 1998. "Conversaciones episcolares (sobre la antropología poética y otras yerbas)". Seminario Antropología, Representación, Poética. Encuentro, Diálogo, Exhibición. Ancud, Chile.

Rehaag, Irmgard. 2006. "Reflexiones acerca de la interculturalidad". CPU-e Revista de Investigación Educativa 2: 1-19.

Reynoso, Carlos. 2003. El surgimiento de la antropología postmoderna. Barcelona: Gedisa.

Restrepo, Eduardo. 2012. "Antropologías disidentes". Cuadernos de Antropología Social 35: 55-69.

Rodrigo Alsina, Miquel. 2003. "Violencias interculturales". Sphera Pública 3: 173-188. 2012. La comunicación intercultural. Barcelona: Anthropos.

SERVINDI. 2005. Interculturalidad: Desafio y proceso en construcción. Manual de capacitación. Lima: SINCO.

Surian, Alessio. 2012. "Aprendizaje y competencias interculturales". Ra Ximhai 8.2: 205-222.

Van Dijk, Teun. 1993. Estructuras y funciones del discurso. México D.F.: Siglo XXI.

Valenzuela, Pilar. 2012. "Entre antropología y literatura: Recepción de El umbral roto. Escritos en antropología poética". Acta Literaria 45: 137-151. . 2013a. El diario de viaje/campo como literatura antropológica en Chile. Tesis doctoral. Valdivia: Universidad Austral de Chile.

2013b. "Interculturalidad en la literatura antropológica en Chile". VIII Congreso Internacional de Semiótica. Semiótica, Educación y Cultura. Concepción, Chile. 
